\title{
Re: Choi KC, Park CK. Percutaneous Endoscopic Lumbar Discectomy for L5-S1 Disc Herniation: Consideration of the Relation between the Iliac Crest and L5-S1 Disc
}

\section{To THE EdITOR:}

We read with interest the article "Percutaneous Endoscopic Lumbar Discectomy for L5-S1 Disc Herniation: Consideration of the Relation between the Iliac Crest and L5-S1 Disc' by Choi and Park (1). The authors first proposed a grading system for high iliac crest based on the relationship between the highest point of the iliac crest and the adjacent bony markers. They considered a suprailiac or transiliac approach provided direct visualization of the extruded disc. However, the suprailiac approach is not above the highest point of the iliac crest. Actually, the posterosuperior margin of the iliac crest, lower than the top of the iliac crest, is the real position where puncture needle and working cannula contact to the ilium (Figure). The grading system indirectly reflects the relationship between the ilium and puncture needle, that explained why the puncture is available in the patient with the relative high iliac crest (grade $\geq 5$ ) in clinical practice.

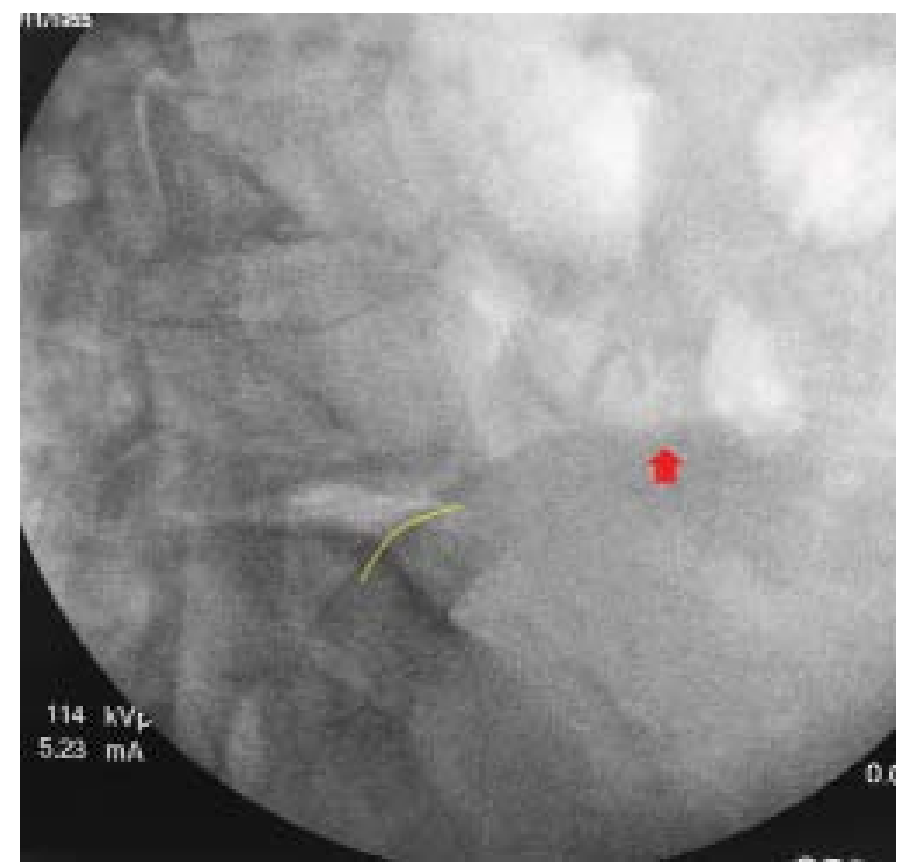

The unique anatomic features of L5-S1 include a large facet joint, narrow intervertebral foramen, small disc height, and an inclination of disc space. They recommended that the iliac height grade $\geq 5$ is the threshold of foraminoplasty for transforaminal endoscopic L5-S1 discectomy. However, besides the trajectory of puncture needle and the location of the protruding nucleus pulposus, whether the foraminoplasty is necessary is also related with the severity of the stenosis of the intervertebral foramen and the size of facet joint. In the patient selections, the latter two factors were neglected. They all affected the rigor of the conclusion and should be mentioned in the limitation.

\author{
Jun-Song Yang, MD \\ Department of Spine Surgery \\ Honghui Hospital \\ Xi'an Jiaotong University,
}

Fig. 1. The oblique fluoroscopy showed the highest point of the iliac crest (red arrow) and the posterosuperior margin of the iliac crest (yellow curve). 
No. 76 Nanguo Road, Xi'an

Shaanxi, 710054, China

Kai-Xuan Liu, MD

Atlantic Spine Center

475 Prospect Avenue, Suite 110

West Orange, NJ 07052, USA

Hong Fan, MD

Department of Spine Surgery

Honghui Hospital

Xi'an Jiaotong University,

No. 76 Nanguo Road, Xi'an

Shaanxi, 710054, China

Tuan-Jiang Liu, MD

Department of Spine Surgery

Honghui Hospital
Xi'an Jiaotong University, No. 76 Nanguo Road, Xi'an

Shaanxi, 710054, China

Peng Liu, MD

Department of Spine Surgery

Honghui Hospital

Xi'an Jiaotong University,

No. 76 Nanguo Road, Xi'an

Shaanxi, 710054, China

Ding-Jun Hao, MD

Department of Spine Surgery

Honghui Hospital

Xi'an Jiaotong University, No. 76 Nanguo Road, Xi'an

Shaanxi, 710054, China

E-mail: dingjun.hao@qq.com

\section{REFERENCES}

1. Choi KC, Park CK. Percutaneous endoscopic lumbar discectomy for $\mathrm{L}_{5}$-S 1 disc herniation: Consideration of the relation

between the iliac crest and $\mathrm{L}_{5}-\mathrm{S}_{1}$ disc.

Pain Physician 2016; 19:E301-308. 


\section{In Response to Re: Choi KC, Park CK. Percutaneous Endoscopic Lumbar Discectomy}

Thank you for your interest in our article.

The entry point is usually just above iliac crest for L5-S1 transforaminal approach (Fig.1.).

The highest point of the ilium (just above the ilium) is the same meaning with the posterosuperior margin of the iliac crest which you mentioned.

In terms of the study limitation, I simplified the complexity of L5-S1 level and iliac bone by 2D radi- ography for conventional transforaminal endoscopic discectomy. This study was only focused on relation between L5-S1 disc space and iliac crest. As you know, entry point, approach angle, working cannula location, necessity of foraminoplasty depend on disc height, foraminal stenosis, the height of iliac crest and disc location in all lumbar levels $(1,2)$.
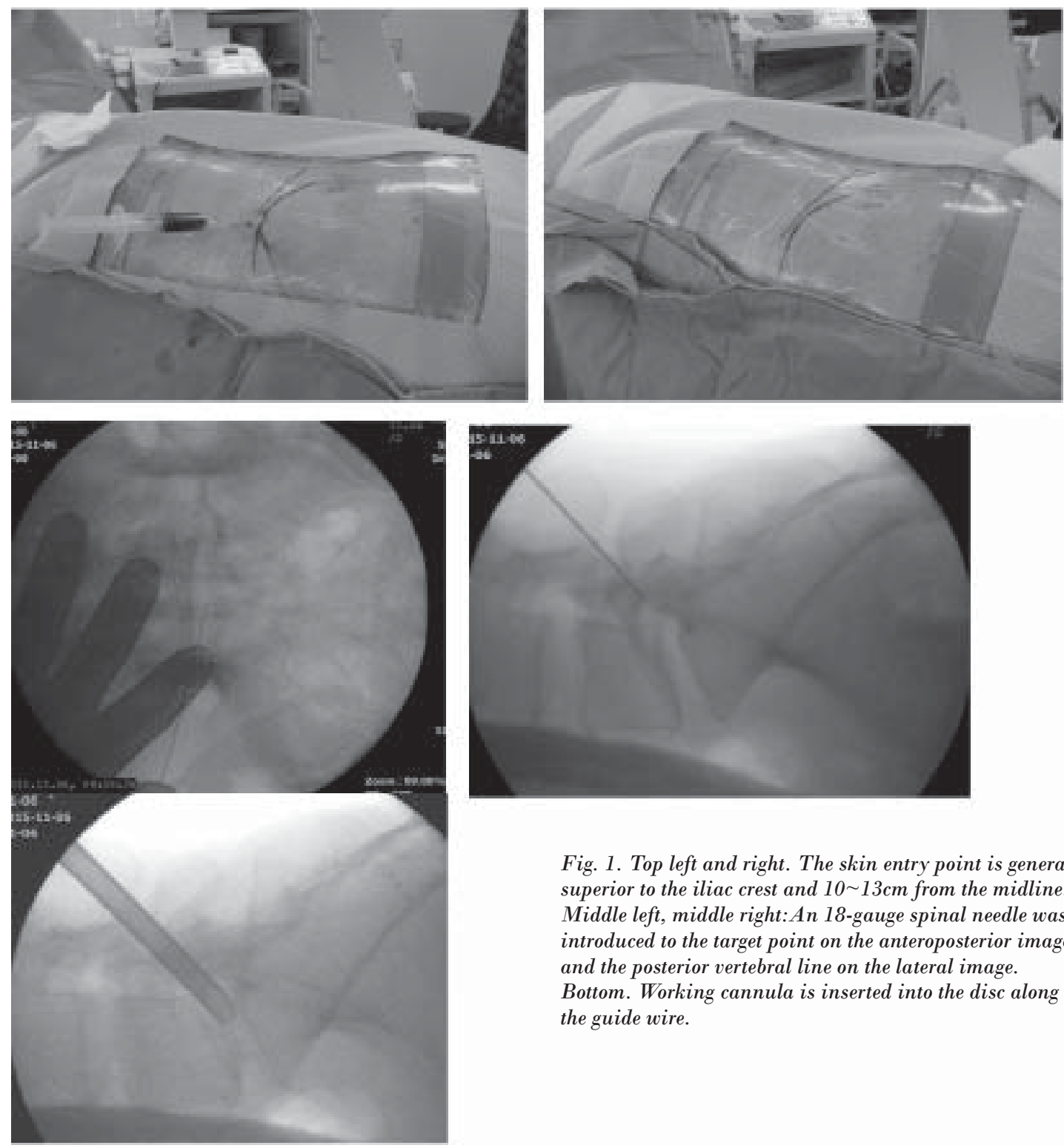

Fig. 1. Top left and right. The skin entry point is generally superior to the iliac crest and $10 \sim 13 \mathrm{~cm}$ from the midline. Middle left, middle right:An 18-gauge spinal needle was introduced to the target point on the anteroposterior image and the posterior vertebral line on the lateral image.

Bottom. Working cannula is inserted into the disc along the guide wire. 
Pain Physician: May/June 2019; 22:E:

Kyung-Chul Choi MD, PhD

Department of Neurosurgery

Leon Wiltse Memorial Hospital,

Anyang, Korea

560 Gyeongsu-daero, Dongan-gu, Anyang-si

Gyeongi-do, 431-841

Republic of Korea

E-mail: spinedochoi@gmail.com
Choon-Keun Park MD, PhD

Department of Neurosurgery

The Leon Wiltse Memorial Hospital

Anyang, Korea

560 Gyeongsu-daero, Dongan-gu, Anyang-si

Gyeongi-do, 431-841

Republic of Korea

\section{REFEREnCES}

1. Choi KC, Shim HK, Park CJ, Lee DC, Park CK. Usefulness of percutaneous endoscopic lumbar foraminoplasty for lumbar disc herniation. World Neuro- surg 2017; 106:484-492. doi: 10.1016/j. wneu.2017.07.035. Epub 2017 Jul 16

2. Choi KC, Lee DC, Shim HK, Shin $\mathrm{SH}$, Park CK. A strategy of percuta- neous endoscopic lumbar discectomy for migrated disc herniation. World Neurourg 2017; 99:259-266. doi: 10.1016/j. wneu.2016.12.052. Epub 2016 Dec 23. 